\title{
Isfahan Thyroid Cohort Study (ITCS)
}

Samaneh Shahrokh Esfahani, PhD'; Aliye Tabatabaee, MSc'; Ashraf Aminorroaya, MD ${ }^{1 *}$; Masoud Amini, MD ${ }^{1}$; Awat Feizi, PhD ${ }^{2}$; Mohsen Janghorbani, PhD $^{1}$; Azamosadat Tabatabaei, MD $^{1}$; Rokhsareh Meamar, PhD ${ }^{3}$; Atoosa Adibi'; Majid Abyar, MSc'; Mozhgan

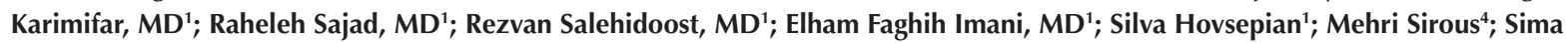
Aminorroaya Yamini, PhD $^{5}$

${ }^{1}$ Isfahan Endocrine and Metabolism Research Center, Isfahan University of Medical Sciences, Isfahan, Iran

${ }^{2}$ Department of Epidemiology and Biostatistics, Isfahan University of Medical Sciences, Isfahan, Iran

${ }^{3}$ Isfahan Clinical Toxicology Research Center, Isfahan University of Medical Sciences, Isfahan, Iran

${ }^{4}$ Department of Radiology, Isfahan University of Medical Sciences, Iran

${ }^{5}$ Department of Engineering and Mathematics, Sheffield Hallam University, Sheffield, UK

\begin{abstract}
Background: The Isfahan Thyroid Cohort Study (ITCS) is one of the few population-based epidemiological studies in Iran that investigates the prevalence and incidence of thyroid disorders including hypothyroidism, hyperthyroidism, goiter, nodule, and iodine status.

Methods: This cohort is located in Isfahan, Iran. The first phase was initiated in 2006 with 2523 participants (1275 males, 1248 females). The participants were selected using multi-stage cluster sampling from the general residents of Isfahan, Iran. The study had two phases (2006 and 2011) and its third stage is planned for 2020-2021.

Results: The prevalence of thyroid function states was euthyroid (89.3\%, 95\% Cl: 88\%-90\%), overt hypothyroidism ( $2.8 \%, 95 \%$ Cl: $2 \%-3 \%$ ), subclinical hypothyroidism $(5.8 \%, 95 \% \mathrm{Cl}: 4 \%-6 \%)$, overt hyperthyroidism $(0.8 \%, 95 \% \mathrm{Cl}: 0.4 \%-1 \%)$, and subclinical hyperthyroidism $(0.99 \%, 95 \% \mathrm{Cl}: 0.6 \%-1 \%)$. Hypothyroidism and hyperthyroidism were significantly associated with goiter. The incidence of thyroid dysfunction was reported as follows: overt hypothyroidism (2.7, 95\% Cl: 1.6-3.7), subclinical hypothyroidism (20.6, 95\% Cl: 18-23), overt hyperthyroidism (1.9, 95\% Cl: 1-2.7) and subclinical hyperthyroidism $(2.7,95 \% \mathrm{Cl}: 1.6-3.7)$ per 1000 (person-year).

Conclusion: We assessed the prevalence and incidence of thyroid disorders in Isfahan in the first and second phase, respectively. We are conducting the third phase of the ITCS in order to study the associations between thyroid peroxidase antibody (TPOAb) level and environmental factors such as infection.

Keywords: Cohort studies, Goiter, Hyperthyroidism, Hypothyroidism

Cite this article as: Shahrokh Esfahani S, Tabatabaee A, Aminorroaya A, Amini M, Feizi A, Janghorbani M, et al. Isfahan thyroid cohort study (itcs). Arch Iran Med. 2021;24(11):788-795. doi: 10.34172/aim.2021.118
\end{abstract}

Received: November 29, 2020, Accepted: April 21, 2021, ePublished: November 1, 2021

\section{Introduction}

Thyroid dysfunctions are the most common endocrine disorders after diabetes. ${ }^{1}$ Thyroid hormones regulate differentiation, growth, and metabolism throughout life. ${ }^{2}$ These hormones play important roles in regulating carbohydrate and lipid metabolism, ${ }^{3,4}$ neural development and occurrence of cognitive impairment disorders such as Alzheimer's disease (AD). ${ }^{5}$ Thyroid hormones also affect cardiovascular function, ${ }^{6}$ and thyroid disorders are proved to be associated with heart failure, coronary artery disease, and even cardiovascular mortality risk. ${ }^{7,8}$

The prevalence and pattern of thyroid disorders vary substantially across countries. ${ }^{8,9}$ A study of congenital hypothyroidism $(\mathrm{CH})$ in Isfahan (launched in 2002) reported permanent and transient rates of 1:748 and 1:1114 births, respectively, ${ }^{10}$ while the incidence of permanent $\mathrm{CH}$ in Greece ${ }^{11}$ and Saudi Arabia ${ }^{12}$ were reported to be 1:1800 and 1:1400 births, respectively.

The prevalence rate of thyroid disorders depends on ethnicity, geographical regions, autoimmunity, genetic, and environmental factors. One of these environmental factors is iodine intake status. Isfahan is considered as an iodine replete area following the national salt iodization in $1994 .{ }^{\circ}$

There is a very limited number of cohort studies that have investigated thyroid disorders in Iran, ${ }^{13}$ and the Isfahan Thyroid Cohort Study (ITCS) is one of the few populationbased epidemiological studies, focusing on the prevalence and incidence of thyroid disorders. The Isfahan Thyroid Cohort Study has been carried out in two phases. The first phase aimed to investigate the prevalence of thyroid disorders, including hypothyroidism, hyperthyroidism, goiter, nodule, and iodine status, and to determine whether iodine intake had any effect on the prevalence of thyroid disorders in the community, subsequent to 15 years of salt iodization. Furthermore, ultrasonographic evaluation of thyroid was performed in a small portion of the population to assess volume, size, and echogenicity of nodules. The second phase investigated the incidence of thyroid dysfunction in those participants who were euthyroid in the first phase in 2006. The role of thyroid peroxidase antibody (TPOAb) and thyroid-stimulating hormone (TSH) in predicting thyroid dysfunction was also assessed in the second phase. The Isfahan Thyroid

*Corresponding Author: Ashraf Aminorroaya, MD, Isfahan Endocrine and Metabolism Research Center, Khorram Street, Jomhouri Square, Isfahan, Iran. Email: aminorroaya@med.mui.ac.ir 
Cohort Study was carried out in the Isfahan Endocrine and Metabolism Research Center (IEMRC).

\section{Material and Methods \\ Study Participants}

Isfahan is centrally located in Iran. It is the third-largest city of the country and is 1590 meters above sea level. The Isfahan Thyroid Cohort Study was launched in 2006 when the estimated population of Isfahan was around 2 million. Participants were included in the study if they were (a) residents of Isfahan, (b) Iranian citizens, (c) older than 20 years, and (d) willing to provide informed consent. A sample size of 2511 was considered based on a prevalence rate of $3 \%$ for hypothyroidism, $5 \%$ type one error rate, with a precision of $0.7 \%$, after accounting for a maximum nonresponse rate of $10 \%{ }^{8}$

The participants were selected using multistage cluster sampling. Forty blocks were randomly selected from the city map via the post office. The mailing addresses of houses in these 40 blocks were provided accordingly. Then, 960 houses were chosen randomly (24 houses in each block) to be approached.

Twenty trained staff went door-to-door to inform and invite all adult individuals to take part in the cohort study. The leader of the group was a retired employee of the Isfahan Health Center with several years of experience in epidemiological fieldwork. They hand-picked 20 experienced health center staff and trained them for the door-to-door mission. During the face-to-face invitation, the study team explained to the potential participants which type of tests and examinations would be carried out. The objectives of the study and its contribution to healthcare decision-making were also explained.
Interestingly, one of the main reasons that many people agreed to participate in the study was to take part in improving medical care conditions in the city. In total, 2600 general residents of Isfahan aged more than 20 years old were invited, and 2523 (97\% participation rate) accepted the invitation. Informed verbal consent was obtained from all individuals before their recruitment in the study (in the third phase, informed written consent is obtained) (Figure 1).

An invitation was issued for general practitioners (GPs) to participate in the project. Seven volunteers were selected and trained. The principal investigator (PI), an endocrinologist, trained GPs to examine the thyroid, search for possible nodules or goiter, and fill the checklist. An appointment was scheduled for each participant to attend a temporary cohort unit. The initial stage of examinations was established in a temporary cohort unit, with enough rooms and space to receive a large number of participants. This temporary building was located in a convenient part of the city with easy access to major transport links. The appointment session included physical examination, blood sample collection, and filling a questionnaire checklist. Ultrasound imaging was performed on two randomly selected subgroups and urine samples were collected from them. The results of the tests were mailed to participants. Subjects with abnormal results (on physical examinations and/or laboratory tests) were recalled and examined by an endocrinologist (PI) in the IEMRC for further assessment. If the PI confirmed abnormal blood test and/or physical examination results, a treatment plan was suggested, and the patient was referred to clinics or specialists for future follow-up visits.

In the second phase of the study, 723 subjects were

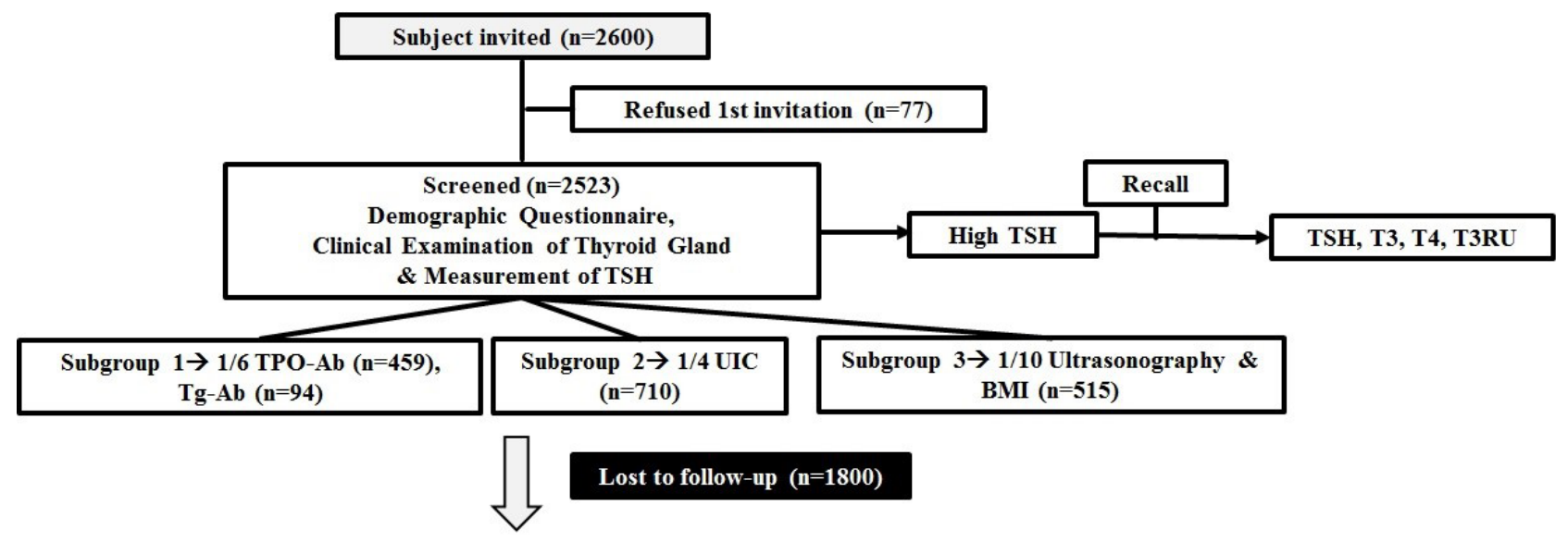

Second phase invitation $(n=723)$

Passed away $(\mathrm{n}=9)$

Refused 2st invitation $(n=3)$

Screened $(n=711)$

Demographic Questionnaire,

Clinical Examination of Thyroid Gland, BMI \&

Blood samples $\rightarrow$ T4, T3, TSH, TPO-Ab, Tg-Ab and FPG 
invited to take part, of whom 711 participated in the study for follow-up (98\% response rate) (Figure 1). Participants attended the IEMRC according to scheduled appointments. The visit consisted of a physical examination and blood sample collection. In this phase of the study, a trained, experienced GP and two endocrinologists performed the physical examination, and filled the checklists.

\section{Follow-up}

Participants were evaluated and followed up by the study team for thyroid disorders, such as hypothyroidism, hypothyroidism, goiter, and nodules.

- $\quad$ First phase: The study started in 2006.

- Second phase: This stage of the cohort study was initiated in 2011.

- Third phase: The third phase is focused on autoimmune thyroid diseases. This phase is planned for 2020-2021; recruiting started in January, but was halted temporarily due to the COVID-19 crisis. All participants of the second phase (711 participants) are considered for the third phase. We estimated more than 500 participants for this phase. The following data are being collected for this phase: demographic and general data, anthropometric data, fertility and pregnancy history, medical history, blood test, and physical examination results (Table 1).

\section{Loss to Follow-up}

Due to significant changes in phone numbers, following upgrades made to the infrastructure of the city (Isfahan), and lack of funding to take other means of contacting participants, only 723 participants could be contacted in 2011, of whom 711 agreed to be engaged with the second phase of the study, nine had passed away, and three rejected our invitation because of personal reasons. The reasons for the deaths were road accidents $(n=2)$, cerebrovascular accident $(n=2)$, colorectal cancer $(n=1)$, lung cancer $(n=1)$, and heart attack $(n=3)$. Although the study experienced a significant attrition rate in the second phase, it still served its purpose of investigating thyroid disorder incidences and the role of TSH and TPOAb values in predicting thyroid disorders. In order to make sure that there is no selection bias due to the loss to follow-up in the $2^{\text {nd }}$ phase, we compared the characteristics of individuals between the followed and not-followed participants at the baseline.

\section{Measurements}

Phase One

The first stage included an examination and face-to-face interview of participants by trained interviewers (GPs). The GPs examined the participants' thyroid gland for consistency and possible goiter [according to the WHO and clinical criteria ${ }^{14,15}$ and nodules.

Demographic data including gender, age, and education; medical history including previous laboratory results, thyroid disorders, and medication history; and parity and menopause status of all participants were collected.
Table 1. Data Collected in ITCS

\begin{tabular}{|c|c|c|c|}
\hline & Phase 1 & Phase 2 & Phase 3 \\
\hline \multicolumn{4}{|l|}{ Demographic and general data } \\
\hline Gender & $*$ & $*$ & $*$ \\
\hline Age & $*$ & * & * \\
\hline Education & $*$ & & $*$ \\
\hline Marital status & & $*$ & $*$ \\
\hline Smoking & & $*$ & $*$ \\
\hline \multicolumn{4}{|l|}{ Anthropometric data } \\
\hline Height & $*$ & $*$ & $*$ \\
\hline Weight & * & * & $*$ \\
\hline Waist & & $*$ & $*$ \\
\hline BMI & * & * & $*$ \\
\hline \multicolumn{4}{|l|}{ Fertility and pregnancy } \\
\hline Gravidity & & $*$ & * \\
\hline Parity & & $*$ & $*$ \\
\hline Current pregnancy & * & * & * \\
\hline Miscarriage & & * & * \\
\hline Infertility & & * & * \\
\hline $\begin{array}{l}\text { Delivery method (natural birth, } \\
\text { C-section) }\end{array}$ & & * & * \\
\hline Menstrual period & & $*$ & $*$ \\
\hline Menopause & * & * & * \\
\hline \multicolumn{4}{|l|}{ Medical history } \\
\hline Thyroid disorders & $*$ & $*$ & $*$ \\
\hline Other disorders & & $*$ & $*$ \\
\hline $\begin{array}{l}\text { Previous sonography, blood and/or } \\
\text { pathology test results }\end{array}$ & $*$ & * & * \\
\hline Family history of thyroid disorders & & * & * \\
\hline $\begin{array}{l}\text { Medication history (Levothyroxine, } \\
\text { Metimazol, radioactive iodine) }\end{array}$ & * & $*$ & $*$ \\
\hline Thyroid surgery & & * & * \\
\hline \multicolumn{4}{|l|}{ Blood and urinary tests } \\
\hline TSH & * & * & * \\
\hline T3 & $*$ & * & \\
\hline T4 & $*$ & * & * \\
\hline $\mathrm{T} 3 \mathrm{Ru}$ & $*$ & & \\
\hline TPO-Ab & * & * & * \\
\hline FPG & $*$ & & \\
\hline $\begin{array}{l}\text { Anti-Helicobacter pylori } \\
\text { immunoglobulin G (IgG) }\end{array}$ & & & * \\
\hline Urinary iodine concentration & $*$ & & \\
\hline \multicolumn{4}{|l|}{ Physical examination } \\
\hline Blood pressure & & $*$ & $*$ \\
\hline Goiter & $*$ & * & * \\
\hline Nodule & $*$ & * & * \\
\hline Sonographic thyroid features & * & & \\
\hline
\end{tabular}

General practitioners examined all participants for possible thyroid goiter and nodules.

Blood samples were collected from all subjects. These samples were analyzed and stored at the IEMRC preceded 
by a centrifuge and freezing $\left(\right.$ at $\left.-20^{\circ} \mathrm{C}\right)$ in a laboratory next to the temporary cohort unit. Serum TSH was assessed by immunoradiometric assay (Kavoshyar Co., Tehran, Iran). Serum TPOAb and TgAb were measured by Rapid ELISA (Genesis Diagnostic Products Corp.). Serum T4, T3, and T3RU were measured by radioimmunoassay (Kavoshyar Co., Tehran, Iran).

TSH was measured for all participants, while urinary iodine concentration (UIC) and TPOAb were evaluated for about one-fourth and one-sixth of randomly selected subjects, respectively. Around one-tenth of randomly selected participants were assessed by ultrasonography. Ultrasound imaging was carried out to assess the volume, size, and echogenicity of nodules. Height and weight were also measured for this subgroup. In the second stage of the study, the participants with a history of thyroid diseases or abnormal physical examination and TSH analysis were recalled. Blood samples were collected from these patients again to measure TSH, T4, T3, and T3RU.

\section{Phase Two}

In the second phase of the study, all assessments were conducted on all participants. One GP interviewed participants and filled a detailed checklist. Then, physical examination was carried out. The following data were collected (Table 1):

- Demographic and general data: age, sex, marital and smoking status

- Physical examination: Physical examination was carried out to look for consistency and possible goiter [according to the WHO and clinical criteria ${ }^{14,15}$ and nodules

- Medical history: Thyroid disorders (hyperthyroidism, hypothyroidism, thyroid nodule, goiter and cancer), other types of disorders (acute coronary syndrome, hypertension, other cardiovascular diseases, diabetes mellitus, hyperlipidemia), family history of thyroid disorders, previous medical results, thyroid surgery, and medication history

- Fertility and pregnancy history: gravity, parity, current pregnancy, miscarriage, infertility, delivery method, menstrual period, and menopause

- Anthropometric measures (height, weight, waist, and body mass index [BMI])

- Blood pressure: Blood pressure was measured twice using a mercury sphygmomanometer while the subjects were in a seated position, with at least a 30-second interval between measurements. The mean of two measurements was recorded as the subject's blood pressure.

- Blood sample analysis including TSH, T3, T4, TPOAb, and fasting plasma glucose (FPG): Serum total $\mathrm{T} 4$ and $\mathrm{T} 3$ were analyzed by radioimmunoassay (Kavoshyar Co., Tehran, Iran). Serum TSH concentration was assessed by immunoradiometric assay (KavoshyarCo., Tehran, Iran). Serum TPOAb and TgAb were measured with Rapid ELISA (Genesis
Diagnostic Products Corp.). FPG (mg/dL) was measured by photometric method (Pars Azmon kit Lot number: 94011).

\section{Statistical Analysis}

Continuous and categorical variables are expressed as means (standard error -SE) or 95\% confidence intervals (CIs) and frequency (percentages), respectively, unless specified otherwise. Normality of continuous data was evaluated using Kolmogorov-Smirnov test and Q-Q plot. Non-normal continuous data are reported as median (interquartile range: First(Q1) -Third(Q3) quartiles). Statistical methods included the independent samples Student's t-test or Mann-Whitney U test. Oneway analysis of variance followed by the one-way post hoc Tukey test or nonparametric Kruskal-Wallis test were used for comparing normally and non-normally distributed continuous variables. Chi-square test, or Fisher's exact test and binary logistic regression were used to analyze categorical data. Correlation analysis was performed using Spearman's rho correlation coefficient; age adjustment was performed to determine the linear relationship between UIC results and blood serum TSH levels. Age-standardized means were considered and compared using general linear models. Binary logistic regression analysis was performed in different models to determine the association between TPOAb as predictor of thyroid dysfunction, as well as TSH levels at year 2006 (first phase) with incidence of hypothyroidism. In all analyses, relative risk (RR) and 95\% confidence interval (95\% CI) were reported in crude and adjusted models; adjustment was made for age, gender, smoking, BMI, positive family history, parity, abortion, age of menopause, having history of goiter or nodules for both dependent variables and being positive TPOAb, TgAb and T4 for hypothyroidism. The ability of TPOAb, TSH, T4, T3, and T3RU to predict thyroid dysfunctions was examined by the receiver operating characteristic (ROC) curve and their respective areas under the curve, in which sensitivity is plotted as a function of 1-specificity. An area under the curve (AUC) above 0.7 was considered to be useful, while an AUC between 0.8 and 0.9 indicated good diagnostic accuracy. All statistical analyses were performed using SPSS 16 for Windows (SPSS Inc., Chicago, IL, USA)

\section{Results \\ Phase One}

At the baseline, 2523 subjects (1275 males, 1248 females) entered the study, aged 20 to 86 years. The mean \pm SE age was $39 \pm 0.25$ years. In total, $89.3 \%$ (2254) of the included subjects were euthyroid, while thyroid disorders were identified in the rest of participants: $2.8 \%$ overt hypothyroidism, 5.8\% subclinical hypothyroidism, $0.8 \%$ overthyperthyroidism, and $1 \%$ subclinical hyperthyroidism. ${ }^{8}$

Urinary iodine concentration measurements for 710 participants showed that 425 (59.9\%) subjects had sufficient iodine, while iodine deficiency and excess were detected in 
$152(21.4 \%)$ and 133 (18.7\%) participants, respectively. No statistically significant correlation was observed between UIC results and blood serum TSH levels $(r=0.024$, $P=0.520){ }^{8,9}$ In total, goiter was identified in $19 \%(\mathrm{n}=478)$ of subjects. The rates of grade I and II goiter were $12.4 \%$ $(\mathrm{n}=312)$ and $6.6 \%(\mathrm{n}=166)$, respectively. ${ }^{9}$ Hypothyroidism and hyperthyroidism were significantly associated with goiter. Hypothyroidism was observed in $18.6 \%$ (89/478) of participants with goiter, compared to $6.4 \%(130 / 2045)$ of the non-goitrous participants (odds ratio $[\mathrm{OR}]=3.6,95 \%$, CI 2.7-4.9, $P=0.001)$. Hyperthyroidism was observed in $5.2 \%(29 / 478)$ of subjects with goiter, compared to $0.8 \%$ $(17 / 2045)$ of non-goitrous participants $(\mathrm{OR}=9.0,95 \% \mathrm{CI}$ 4.9-16.6, $P=0.001){ }^{16}$

In the first phase of the study, participants were evaluated for possible nodules by physical examination and ultrasonography. Palpable thyroid nodules were observed in $62(2.5 \%)$ participants out of a total of 2523; 56 of whom had single and six had multiple nodules. The nodules were distributed unevenly with 38 of the nodules located in the right lobe, 18 in the left lobe, and none in isthmus. ${ }^{17}$

Among those participants who were assessed by ultrasonography $(n=268)$, the prevalence of thyroid incidentaloma, nodules that were undetectable by physical examination, was $13.2 \%(n=31)$, consisting of 22 single nodules and 9 multiple nodules. According to ultrasonography results, $58.5 \%, 15.1 \%$, and $29 \%$ of thyroid incidentalomas were hypoechogenic, hyperechogenic, and hypo-hyperechogenic, respectively. Also, 3.8\% of all nodules were calcified. ${ }^{18,19}$ Ultrasonography imaging indicated that the thyroid volume in patients with incidentaloma was larger than those without it $[11.9 \pm 1 \mathrm{~mL}$ vs. $9.8 \pm 0.26 \mathrm{~mL}, P=0.001] .{ }^{18}$ The mean volume of thyroid lobes was $9.53 \pm 0.65 \mathrm{~mL}$ in this subgroup. A statistically significant correlation was noticed between thyroid volume and subjects' heights $(\mathrm{r}=0.48, P<0.001)^{20}$ (Table 2$)$.

\section{Phase Two}

The second phase of the study included 338 male and 372 female subjects with a mean \pm SE age of $47.28 \pm 0.45$ years, ranging from 25 to 82 years. The incidence of thyroid dysfunction was reported as follows: overt hypothyroidism (2.7, 95\% CI: 1.6-3.7), subclinical hypothyroidism (20.6, 95\% CI: 18-23), overt hyperthyroidism (1.9, 95\% CI: 1-2.7) and subclinical hyperthyroidism (2.7, 95\% CI: 1.6-3.7) per 1000 (person-year). ${ }^{1}$

The results of the second phase showed significantly

Table 2. Phase 1 Findings (in 2006)

\begin{tabular}{|c|c|c|c|}
\hline & Men & Women & Total \\
\hline \multicolumn{4}{|l|}{ Blood and urinary tests } \\
\hline Urinary iodine $(\mu \mathrm{g} / \mathrm{dL})$ & $20.00 \pm 0.76$ & $20.0 \pm 0.76$ & $20.35 \pm 0.49$ \\
\hline Serum TSH (mIU/L) & $1.7(1.1-2.4)$ & $2(1.3-3)$ & $1.80(1.2-2.7)$ \\
\hline TPOAb (IU/mL) & $9(2-161)$ & $8.35(2.3-99)$ & $8.60(2.4-122)$ \\
\hline $\mathrm{T} 3(\mathrm{ng} / \mathrm{dl})$ & $136.06 \pm 2.31$ & $134.84 \pm 1.84$ & $135.20 \pm 1.46$ \\
\hline $\mathrm{T} 4(\mu \mathrm{g} / \mathrm{dl})$ & $6.37 \pm 0.16$ & $6.74 \pm 0.10$ & $6.63 \pm 0.12$ \\
\hline \multicolumn{4}{|l|}{ Goiter status } \\
\hline No & $\begin{array}{c}1157 \\
(90.7 \% ; 95 \% \mathrm{Cl}: 89 \%-91 \%)\end{array}$ & $\begin{array}{c}888 \\
(71.2 \% ; 95 \% \mathrm{Cl}: 69 \%-72 \%)\end{array}$ & $\begin{array}{c}2045 \\
(81.1 \% ; 95 \% \mathrm{Cl}: 79 \%-82 \%)\end{array}$ \\
\hline Grade I & $\begin{array}{c}96 \\
(7.5 \% ; 95 \% \mathrm{Cl}: 6 \%-8 \%)\end{array}$ & $\begin{array}{c}216 \\
(17.3 \% ; 95 \% \mathrm{Cl}: 15 \%-18 \%)\end{array}$ & $\begin{array}{c}312 \\
(12.4 \% ; 95 \% \mathrm{Cl}: 11 \%-13 \%)\end{array}$ \\
\hline Grade II & $\begin{array}{c}22 \\
(1.7 \% ; 95 \% \mathrm{Cl}: 1 \%-2 \%)\end{array}$ & $\begin{array}{c}144 \\
(11.5 \% ; 95 \% \text { Cl: } 10 \%-12 \%)\end{array}$ & $\begin{array}{c}166 \\
(6.6 \% ; 95 \% \mathrm{Cl}: 5 \%-7 \%)\end{array}$ \\
\hline \multicolumn{4}{|l|}{ Nodule } \\
\hline No & $\begin{array}{c}1258 \\
(98.7 \% ; 95 \% \mathrm{Cl}: 98 \%-99 \%)\end{array}$ & $\begin{array}{c}1203 \\
(96.4 \% ; 95 \% \mathrm{Cl}: 95 \%-97 \%)\end{array}$ & $\begin{array}{c}2461 \\
(97.5 \%, 95 \% \text { Cl: } 96 \%-98 \%)\end{array}$ \\
\hline Yes & $\begin{array}{c}17 \\
(1.3 \% ; 95 \% \mathrm{Cl}: 0.8 \%-1 \%)\end{array}$ & $\begin{array}{c}45 \\
(3.6 \% ; 95 \% \mathrm{Cl}: 2 \%-4 \%)\end{array}$ & $\begin{array}{c}62 \\
(2.5 \% ; 95 \% \mathrm{Cl}: 1 \%-3 \%)\end{array}$ \\
\hline \multicolumn{4}{|c|}{ Prevalence of thyroid dysfunction } \\
\hline Euthyroid & $\begin{array}{c}1199 \\
(94.0 \% ; 95 \% \mathrm{Cl}: 93 \%-94.9 \%)\end{array}$ & $\begin{array}{c}1055 \\
(84.5 \% ; 95 \% \mathrm{Cl}: 83 \%-85 \%)\end{array}$ & $\begin{array}{c}2254 \\
(89.33 \% ; 95 \% \mathrm{Cl}: 88 \%-90 \%)\end{array}$ \\
\hline Subclinical hypothyroid & $\begin{array}{c}40 \\
(3.1 \% ; 95 \% \mathrm{Cl}: 0.2 \%-3.7 \%)\end{array}$ & $\begin{array}{c}107 \\
(8.6 \% ; 95 \% \mathrm{Cl}: 7 \%-9 \%)\end{array}$ & $\begin{array}{c}147 \\
(5.8 \% ; 95 \% \mathrm{Cl}: 4 \%-6 \%)\end{array}$ \\
\hline Overt hypothyroid & $\begin{array}{c}20 \\
(1.6 \% ; 95 \% \mathrm{Cl}: 1 \%-2 \%)\end{array}$ & $\begin{array}{c}52 \\
(4.2 \% ; 95 \% \mathrm{Cl}: 3 \%-4.9 \%)\end{array}$ & $\begin{array}{c}72 \\
(2.8 \% ; 95 \% \mathrm{Cl}: 2 \%-3 \%)\end{array}$ \\
\hline Subclinical hyperthyroid & $\begin{array}{c}9 \\
(0.7 \% ; 95 \% \mathrm{Cl}: 0.3 \%-1 \%)\end{array}$ & $\begin{array}{c}16 \\
(1.3 \% ; 95 \% \mathrm{Cl}: 0.8 \%-1.7 \%)\end{array}$ & $\begin{array}{c}25 \\
(0.99 \% ; 95 \% \mathrm{Cl}: 0.6 \%-1 \%)\end{array}$ \\
\hline Overt hyperthyroid & $\begin{array}{c}5 \\
(0.4 \% ; 95 \% \mathrm{Cl}: 0.1 \%-0.6 \%)\end{array}$ & $\begin{array}{c}16 \\
(1.3 \% ; 95 \% \mathrm{Cl}: 0.8 \%-1.7 \%)\end{array}$ & $\begin{array}{c}21 \\
(0.8 \% ; 95 \% \mathrm{Cl}: 0.4 \%-1 \%)\end{array}$ \\
\hline Euthyroid sick syndrome & $\begin{array}{c}2 \\
(0.2 \% ; 95 \% \mathrm{Cl}: 0.02 \%-0.3 \%)\end{array}$ & $\begin{array}{c}2 \\
(0.2 \% ; 95 \% \mathrm{Cl}: 0.02 \%-0.3 \%)\end{array}$ & $\begin{array}{c}4 \\
(0.1 \% ; 95 \% \text { Cl: } 0 \%-0.2)\end{array}$ \\
\hline
\end{tabular}

Data are presented as Mean \pm SE, Median (QR1-QR3), Number (percent). 
higher TSH levels in females, subjects with a positive family history of thyroid disease, and those with positive TPOAb compared to other participants. The median concentrations of TSH and TPOAb in $2011(P=0.001)$ were higher than these values in 2006, especially in women. The follow-up study after 6 years revealed $16.4 \%$ new cases of positive TPOAb, while $16.1 \%$ of previously positive TPOAb cases showed negative values. ${ }^{21}$

Aging showed no association with the risk of thyroid dysfunction, TSH levels, or an increase in the TPOAb level. However, a higher incidence of thyroid dysfunction was observed in people older than 60 years, except for subclinical hyperthyroidism. Interestingly, subjects older than 45 years with positive TPOAb had a higher risk of thyroid dysfunction. ${ }^{1}$

The TSH levels at the baseline showed a positive association with the risk of overt hypothyroidism $(\mathrm{RR}=3.5$ : 95\% CI; 1.27-10.0) and subclinical hypothyroidism $(\mathrm{RR}=8.3: 95 \% \mathrm{CI} ; 4.81-14.60)$ in the second phase. ${ }^{21}$

One of the other objectives of ITCS was to investigate the roles of TSH and TPOAb concentrations in predicting thyroid dysfunction. ROC curve analysis was used to determine the best cutoff values of TSH and TPOAb in 2006. A cutoff value of TSH at $2.05 \mathrm{mIU} / \mathrm{L}$ (AUC [95\% CI]; 0.68 [0.44-0.92]; $P=0.05)$ was obtained for differentiating the patients with overt hypothyroidism from euthyroidism. However, this cutoff value was unattainable when only participants with negative TPO and TgAbs were included. ${ }^{21}$ A TPOAb cutoff value of 38 $\mathrm{IU} / \mathrm{mL}$ was determined for both overt hypothyroidism and hyperthyroidism ${ }^{1}$ (Table 3 ).
A comparison was made between characteristics of the followed (participated in phase 2) and not-followed individuals (those who were in the first phase but did not participate in the second phase) and the results are presented in Table 4. No significant difference was observed between the two groups except for age which was statistically but not clinically significant.

\section{Discussion}

This is the profile of the Isfahan Thyroid Cohort Study conducted since 2006. In the first phase, we captured a picture of thyroid disorders prevalence in Isfahan, Iran and in the second phase, we focused on the incidence of thyroid dysfunction and its risk factors, especially autoimmunity. The prevalence rates of subclinical and overt hypothyroidism in Isfahan (ITCS) and Tehran (TTS) were $5.8 \%$ vs. $5.5 \%$ and $2.8 \%$ vs. $2 \%$, respectively. ${ }^{8,13}$ The prevalence rates (subclinical and overt) for hyperthyroidism in Isfahan and Tehran were $1 \%$ vs. 3.7\% and $0.8 \%$ vs. $2.2 \%$, respectively. Over 6 years of follow-up, both in Isfahan and Tehran, the annual incidence rates of subclinical and overt hypothyroidism were 20.6 vs. 7.62 and 2.7 vs. 2 per 1000 person-years, respectively. ${ }^{1,13}$ The incidence rates for subclinical and overt hyperthyroidism were 2.7 vs. 3.7 and 1.9 vs. 2.2 per 1000 person-years, respectively. In Isfahan, both the prevalence and incidence of hypothyroidism are higher than Tehran and the prevalence and incidence of hyperthyroidism in Tehran are higher than Isfahan. During the period of the study, both cities were iodine sufficient for many years through fortification of salt with iodine. Iodine supplement

Table 3. Phase 2 Findings (in 2011)

\begin{tabular}{lcccc}
\hline & Men & Women & Total \\
\hline Serum TSH $(\mathrm{mlU} / \mathrm{L})$ & $1.80(1.2-2.6)$ & $2.10(1.4-3.1)$ & $2.00(1.3-2.8)$ \\
$\mathrm{TPOAb}(\mathrm{IU} / \mathrm{mL})$ & $42.50(29.25-71.75)$ & $51.00(37-214)$ & $46.00(33-86)$ \\
$\mathrm{T} 4(\mu \mathrm{g} / \mathrm{dL})$ & $8.09 \pm 0.18$ & $8.48 \pm 0.10$ & $8.29 \pm 0.10$ \\
$\mathrm{~T} 3(\mathrm{ng} / \mathrm{dL})$ & $1.75 \pm 0.05$ & $1.71 \pm 0.05$ & $1.73 \pm 0.03$ \\
$\mathrm{FPG}(\mathrm{mg} / \mathrm{dL})$ & $104.63 \pm 1.34$ & $102.87 \pm 1.63$ & $103.73 \pm 1.06$ \\
\hline
\end{tabular}

Data are presented as Mean \pm SE, Median (Q1-Q3).

Table 4. Comparison of Some Baseline Characteristics between the Followed and Not-followed Participants

\begin{tabular}{|c|c|c|c|}
\hline Basal Characteristics & Not Followed Participants & Followed Participants & $P$ Value* \\
\hline Gender & F/M: $48.5 \% / 51.5 \%$ & F/M: $52 \% / 48 \%$ & 0.105 \\
\hline Age (y) & $38.45 \pm 0.29$ & $40.51 \pm 0.44$ & 0.0001 \\
\hline Weight (kg) & $71.25 \pm 0.77$ & $69.54 \pm 0.87$ & 0.171 \\
\hline $\mathrm{BMI}\left(\mathrm{kg} / \mathrm{m}^{2}\right)$ & $26.25 \pm 0.37$ & $26.23 \pm 0.32$ & 0.967 \\
\hline Menopause & $16.7 \%$ & $21.1 \%$ & 0.170 \\
\hline TSH (mIU/L) & $1.8(1.2-2.7)$ & $1.9(1.2-2.7)$ & 0.533 \\
\hline Anti-TPO (IU/mL) & $7.8(1.9-122)$ & $10.7(2.8-117)$ & 0.950 \\
\hline Anti-Tg (IU/mL) & $26(6.5-154)$ & $27(5.9-130)$ & 0.890 \\
\hline Thyroid function (euthyroid) & $89.9 \%$ & $87.9 \%$ & 0.215 \\
\hline Clinical nodule & $2.4 \%$ & $2.5 \%$ & 0.386 \\
\hline
\end{tabular}

Data are presented as Mean \pm SE, Median (Q1-Q3) and percent for continuous and categorical variables. *Resulted from Independent samples t-test or MannWhitney $U$ test for continuous and chi-squared or Fisher's exact tests for categorical variables. 
increases the development of thyroid autoimmunity. In the Isfahan Thyroid Cohort Study, hypothyroidism and hyperthyroidism were associated with positive TPOAb and a cutoff value of $38 \mathrm{IU} / \mathrm{mL}$ was obtained for TPOAb to predict both hypothyroidism and hyperthyroidism. ${ }^{1}$ In the Tehran thyroid study, the optimal cutoff points of TPOAb were 18.38 and $14.77 \mathrm{IU} / \mathrm{mL}$ to predict clinical and subclinical hypothyroidism, respectively. ${ }^{13}$ The prevalence of thyroid nodules was $2.5 \%$ and $13.2 \%$ by physical examination and ultrasonography, respectively. ${ }^{17,18}$ There is no report on nodules in the Tehran thyroid study. It appears that autoimmunity plays a major role in both thyroid dysfunctions.

The prevalence of hyperthyroidism (overt and subclinical) was $1.8 \%$ in our study, which was consistent with previous reports ${ }^{22,23}$ in iodine-sufficient areas. It is worth noting that the ITCS was conducted 15 years after the national salt iodization program and the area was considered as an iodine-replete-environment. ${ }^{9}$ The prevalence of thyroid incidentalomas in our population was similar to previous studies in Seoul (13.2\%, vs $13.4 \%),{ }^{24}$ the three cities of Gdańsk, Sopot, and Gdynia in Poland (8\%), ${ }^{25}$ and in Taipei (18.5\%). ${ }^{26}$

In 2011, the data obtained from the first phase, combined with the data collected from the second phase were used to estimate the incidence of thyroid disorders in our population. The annual incidence of overt and subclinical hypothyroidism was 2.7 and 20.6 per 1000 , respectively. The incidence of overt and subclinical hyperthyroidism was 1.9 and 2.7 per 1000 person-years, respectively. This showed that the incidences of subclinical hypo- and hyperthyroidism were higher than overt hypoand hyperthyroidism in both genders after 6 years of follow-up. Moreover, we observed a positive association between almost all types of thyroid dysfunctions and positive TPOAb in various models. The median of TPO and $\mathrm{Tg}$ autoantibody levels were raised in various thyroid dysfunctions ${ }^{1}$. Accordingly, we are conducting the third phase of the ITCS in order to study the associations between TPOAb level and environmental factors such as infection. This stage of the cohort study started in January 2020, and has been paused since March due to the COVID-19 outbreak. The third phase will be resumed as soon as the crisis is managed.

\section{Strengths and limitations}

Strengths

- This cohort study is one of the few population-based studies of thyroid in Iran. The Tehran Thyroid Study ${ }^{13}$ was conducted in the East of Tehran, whereas the Isfahan Thyroid Cohort Study included all areas of the city.

- A large number of participants were recruited with a $97 \%$ participation rate in the first phase. The study population was statistically appropriate to represent the general population.

- First-hand and original data was assessed in this study instead of previously recorded medical history; the main data was collected by physical examinations and laboratory tests.

- Physical examinations and TSH measurements were performed for all participants.

\section{Limitations}

- Due to the shortage of funds, ultrasound imaging was performed and TPOAb concentration was measured for only a small subgroup of the subjects in the first stage.

- Another limitation that this study faced was that some information, including smoking, parity, gravity, and family history of thyroid disorders, were not recorded in the first phase.

- Significant attrition occurred in the second phase of the study; however, it had no negative effects on the findings. In order to assess possible selection bias in the phase 2 due to the loss to follow-up, we compared the characteristics of the followed and not-followed individuals at the baseline. All characteristics show no statistically significant difference, but the age shows a difference of two years, which is also insignificant clinically.

\section{Authors' Contribution}

AA1 is the PI and has managed the cohort study. AA1 and MA1 have designed and established the study. AT1, SSE, and SAY prepared the manuscript. AA1, MA1, and AF evaluated the manuscript and edited it critically. AF and MJ performed the statistical analysis. MA2 collected and managed the data. All the other authors including MK, RS1, RS2, AT2, RM, AA2, EFI, SH, MS, and ZF contributed to examinations and recording data. All authors have read and agreed with the final manuscript.

\section{Data Accessibility}

Currently the raw data is not available for public. We encourage you to contact Prof. Ashraf Aminorroaya at aminorroaya@med.mui. ac.ir for further information or discussing collaboration options.

\section{Conflict of Interest Disclosures}

The authors declare no competing interests.

\section{Ethical Statement}

The study was approved by the Ethics Committee of the Isfahan University of Medical Sciences. The national ethics code for this study is IR.MUI.MED.REC.1397.181. This cohort study has been registered at Iran Cohort Consortium (ICC) in 2018. Participants provided informed verbal consents. The verbal consent was authorized by the Ethics Committee of the Isfahan University of Medical Sciences. All participants declared verbal consent for their data to be published.

\section{Funding}

Isfahan Endocrine and Metabolism Research Center funded both phases of this project.

\section{Acknowledgment}

We would like to thank Dr Zahra Nezhad nik, Dr Sima Beheshti, Dr Shadab Shateri, Dr Marjan Momen zadeh, Dr Mahnaz Soghrati, Dr Hayedeh Adili pour, Dr Hamid Reza Sirus, and Mr Gholamreza Ebrahimi for their contribution to this project. We would like to acknowledge all the IEMC's personnel who contributed to this study. We also like to thank the Isfahan Endocrine and Metabolism Research Center for funding this project. 


\section{References}

1. Aminorroaya A, Meamar R, Amini M, Feizi A, Tabatabae A, Faghih Imani E. Incidence of thyroid dysfunction in an Iranian adult population: the predictor role of thyroid autoantibodies: results from a prospective population-based cohort study. Eur J Med Res. 2017;22(1):21. doi: 10.1186/s40001-017-0260-2.

2. Yen PM. Physiological and molecular basis of thyroid hormone action. Physiol Rev. 2001;81(3):1097-142. doi: 10.1152/ physrev.2001.81.3.1097.

3. Hage M, Zantout MS, Azar ST. Thyroid disorders and diabetes mellitus. J Thyroid Res. 2011;2011:439463. doi: 10.4061/2011/439463.

4. Walsh JP, Bremner AP, Bulsara MK, O'Leary $\mathrm{P}$, Leedman PJ, Feddema $\mathrm{P}$, et al. Thyroid dysfunction and serum lipids: a community-based study. Clin Endocrinol (Oxf). 2005;63(6):670-5. doi: 10.1111/j.1365-2265.2005.02399.x.

5. Bavarsad K, Hosseini M, Hadjzadeh MA, Sahebkar A. The effects of thyroid hormones on memory impairment and Alzheimer's disease. J Cell Physiol. 2019. doi: 10.1002/ jcp. 28198.

6. Vale C, Neves JS, von Hafe M, Borges-Canha M, Leite-Moreira A. The role of thyroid hormones in heart failure. Cardiovasc Drugs Ther. 2019;33(2):179-88. doi: 10.1007/s10557-01906870-4.

7. Kahaly GJ, Dillmann WH. Thyroid hormone action in the heart. Endocr Rev. 2005;26(5):704-28. doi: 10.1210/er.20030033.

8. Aminorroaya A, Janghorbani M, Amini M, Hovsepian S, Tabatabaei A, Fallah Z. The prevalence of thyroid dysfunction in an iodine-sufficient area in Iran. Arch Iran Med. 2009;12(3):262-70.

9. Aminorroaya A, Amini M, Hovsepian S. Prevalence of hyperthyroidism in Isfahan-Iran, in the year 2006, fifteen years after universal salt iodization: a community based study. Acta Endocrinol. 2008;4(3):273-85. doi: 10.4183/aeb.2008.273.

10. Hashemipour M, Hovsepian S, Kelishadi R, Iranpour R, Hadian R, Haghighi $S$, et al. Permanent and transient congenital hypothyroidism in Isfahan-Iran. J Med Screen. 2009;16(1):116. doi: 10.1258/jms.2009.008090.

11. Skordis N, Toumba M, Savva SC, Erakleous E, Topouzi $M$, Vogazianos $M$, et al. High prevalence of congenital hypothyroidism in the Greek Cypriot population: results of the neonatal screening program 1990-2000. J Pediatr Endocrinol Metab. 2005;18(5):453-61. doi: 10.1515/ jpem.2005.18.5.453.

12. Al-Jurayyan NA, Shaheen FI, Al-Nuaim AA, El-Desouki MI, Faiz A, al Herbish AS, et al. Congenital hypothyroidism: increased incidence in Najran province, Saudi Arabia. J Trop Pediatr. 1996;42(6):348-51. doi: 10.1093/tropej/42.6.348.

13. Amouzegar A, Mehran L, Takyar M, Abdi H, Azizi F. Tehran thyroid study (TTS). Int J Endocrinol Metab. 2018;16(4 Suppl):e84727. doi: 10.5812/ijem.84727.

14. World Health Organization, International Council for Control of lodine Deficiency Disorders \& United Nations Children's
Fund (UNICEF)? Indicators for Assessing lodine Deficiency Disorders and Their Control Through Salt lodization. World Health Organization; 1994.

15. Zimmermann M, Saad A, Hess S, Torresani T, Chaouki N. Thyroid ultrasound compared with World Health Organization 1960 and 1994 palpation criteria for determination of goiter prevalence in regions of mild and severe iodine deficiency. Eur J Endocrinol. 2000;143(6):727-31. doi: 10.1530/ eje.0.1430727.

16. Aminorroaya A, Amini M, Hovsepian S. Prevalence of goitre in Isfahan, Iran, fifteen years after initiation of universal salt iodization. J Health Popul Nutr. 2010;28(4):351-8. doi: 10.3329/jhpn.v28i4.6041.

17. Parham M, Aminorroaya A, Amini M. Prevalence of palpable thyroid nodule in Isfahan, Iran, 2006: a population based study. Exp Clin Endocrinol Diabetes. 2009;117(5):209-13. doi: 10.1055/s-0028-1085469.

18. Jafary F, Aminorroaya A, Amini M, Adibi A, Sirous M, Roohi $\mathrm{E}$, et al. Thyroid incidentaloma in Isfahan, Iran - a populationbased study. Endokrynol Pol. 2008;59(4):316-20.

19. Faghih Imani E, Aminorroaya A, Soheilipour F, Adibi A, Sirous M, Roohi E, et al. Sonographic and functional characteristics of thyroid nodules in a population of adult people in Isfahan. Endokrynol Pol. 2010;61(2):188-91.

20. Adibi A, Sirous M, Aminorroaya A, Roohi E, Mostafavi M, Falah Z, et al. Normal values of thyroid gland in Isfahan, an iodine replete area. J Res Med Sci. 2008;13(2):55-60.

21. Aminorroaya A, Meamar R, Amini M, Feizi A, Nasri M, Tabatabaei A, et al. The TSH levels and risk of hypothyroidism: results from a population based prospective cohort study in an Iranian adult's population. Eur J Intern Med. 2017;41:55-61. doi: 10.1016/j.ejim.2016.12.019.

22. Hollowell JG, Staehling NW, Flanders WD, Hannon WH, Gunter EW, Spencer CA, et al. Serum TSH, T(4), and thyroid antibodies in the United States population (1988 to 1994): National Health and Nutrition Examination Survey (NHANES III). J Clin Endocrinol Metab. 2002;87(2):489-99. doi: 10.1210/ jcem.87.2.8182.

23. Völzke H, Lüdemann J, Robinson DM, Spieker KW, Schwahn C, Kramer A, et al. The prevalence of undiagnosed thyroid disorders in a previously iodine-deficient area. Thyroid. 2003;13(8):803-10. doi: 10.1089/105072503768499680.

24. Kang HW, No JH, Chung JH, Min YK, Lee MS, Lee MK, et al. Prevalence, clinical and ultrasonographic characteristics of thyroid incidentalomas. Thyroid. 2004;14(1):29-33. doi: 10.1089/105072504322783812.

25. Karaszewski B, Wilkowski M, Tomasiuk T, Szramkowska M, Klasa A, Obołończyk L, et al. [The prevalence of incidentaloma-asymptomatic thyroid nodules in the Tricity (Gdansk, Sopot, Gdynia) population]. Endokrynol Pol. 2006;57(3):196-200. [Polish].

26. Hsiao YL, Chang TC. Ultrasound evaluation of thyroid abnormalities and volume in Chinese adults without palpable thyroid glands. J Formos Med Assoc. 1994;93(2):140-4. 